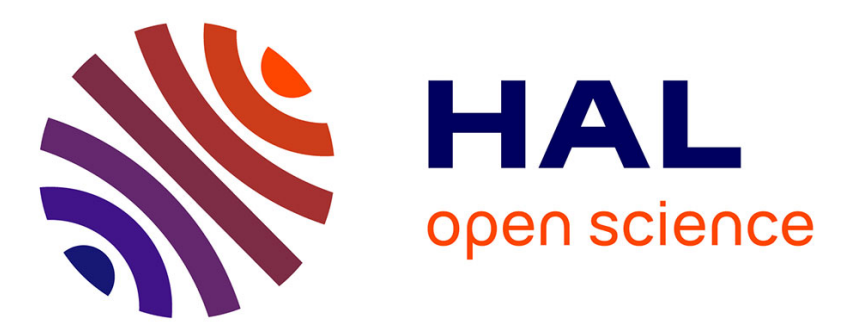

\title{
Elemental and non-elemental olfactory learning using PER conditioning in the bumblebee, Bombus terrestris
}

Frank Sommerlandt, Wolfgang Rössler, Johannes Spaethe

\section{To cite this version:}

Frank Sommerlandt, Wolfgang Rössler, Johannes Spaethe. Elemental and non-elemental olfactory learning using PER conditioning in the bumblebee, Bombus terrestris . Apidologie, 2013, 45 (1), pp.106-115. 10.1007/s13592-013-0227-4 . hal-01234704

\section{HAL Id: hal-01234704 \\ https://hal.science/hal-01234704}

Submitted on 27 Nov 2015

HAL is a multi-disciplinary open access archive for the deposit and dissemination of scientific research documents, whether they are published or not. The documents may come from teaching and research institutions in France or abroad, or from public or private research centers.
L'archive ouverte pluridisciplinaire HAL, est destinée au dépôt et à la diffusion de documents scientifiques de niveau recherche, publiés ou non, émanant des établissements d'enseignement et de recherche français ou étrangers, des laboratoires publics ou privés. 


\title{
Elemental and non-elemental olfactory learning using PER conditioning in the bumblebee, Bombus terrestris
}

\author{
Frank M. J. Sommerlandt, Wolfgang Rössler, Johannes Spaethe \\ Department of Behavioral Physiology and Sociobiology, Biozentrum, University of Würzburg, Am Hubland, \\ 97074, Würzburg, Germany
}

Received 11 February 2013 - Revised 28 May 2013 - Accepted 15 July 2013

\begin{abstract}
Learning olfactory stimuli and their implications is essential in bumblebees for orientation and recognition of nest sites and food sources. To evaluate associative learning abilities in bees under controlled environmental conditions, the proboscis extension response (PER) assay is a well-established method used in honeybees and has recently been successfully adapted to bumblebees. In this study, we examined the cognitive abilities of workers of the eusocial bumblebee, Bombus terrestris, by training individuals in different olfactory learning tasks using classical PER conditioning. We compared learning performance for four different floral odors. Individuals were able to solve absolute $(\mathrm{A}+)$ and differential $(\mathrm{A}+\mathrm{vs} . \mathrm{B}-)$ conditioning tasks, and no differences were found between single odors and odor combinations, respectively. Furthermore, bumblebees performed well on a positive pattern discrimination task (A-, B- vs. $\mathrm{AB}+)$, but failed to solve the negative pattern discrimination $\left(\mathrm{A}+, \mathrm{B}+\right.$ vs. $\left.\mathrm{AB}^{-}\right)$. Our results indicate that workers of $B$. terrestris possess elemental olfactory learning abilities, but, in contrast to previous findings in honeybees, fail in more complex tasks, such as negative pattern discrimination. We discuss possible ultimate causes that have led to the difference in learning capabilities between bumblebees and honeybees.
\end{abstract}

elemental learning / Bombus terrestris / proboscis extension conditioning / bumblebee / configural associations

\section{INTRODUCTION}

Associative learning forms the basis for efficient foraging behavior in bees. It allows bees to relocate specific food sources, efficiently extract pollen and nectar from various flower types, and orientate accurately in time and space (for review see: Menzel and Müller 1996; Dukas 2008). During appetitive conditioning, bees learn to associate a given olfactory, gustatory, visual, or tactile stimulus with a reward (e.g., sucrose solution) by forming an

Electronic supplementary material The online version of this article (doi:10.1007/s13592-013-0227-4) contains supplementary material, which is available to authorized users.

Corresponding author: F.M.J. Sommerlandt, frank.sommerlandt@uni-wuerzburg.de Manuscript editor: Bernd Grünewald elemental association. In nature, stimuli often appear as multimodal blends rather than single elements. Under these conditions, associative learning involves relational dependencies, i.e., the meaning of a given stimulus varies as a function of its occurrence in combination with other stimuli. The processing and learning of complex stimuli is proposed to be accomplished in two different ways as follows (Rudy and Sutherland 1992): in an elemental approach, a complex stimulus is represented by its single elements, in a way that the association between the conditioned stimulus (CS) and the unconditioned stimulus (US) is formed by each element of the CS, i.e., the associative strength of a complex CS equals the sum of the strengths of its elements (elemental learning: Rescorla and Wagner 1972; Couvillon and Bitterman 1988). On the other hand, in a configural approach, the 
representation of a complex CS is achieved as an association, which is distinct from that of the sum of the individual elements. Thus, according to the "unique cue hypothesis," the learned multicomponent stimulus bears specific information which makes it distinguishable from its single elements (configural learning: Rescorla 1972; Wagner and Rescorla 1972; Pearce 1987; Menzel et al. 1999).

Several studies have investigated the elemental (simple linking of two stimuli or a stimulus and a response) and non-elemental (beyond simple linking; Giurfa 2003) olfactory learning abilities in honeybees (Bitterman et al. 1983; Laloi et al. 2000; Deisig et al. 2002, 2003; Komischke et al. 2003), but only little is known about the capabilities of other (eusocial) bee species, e.g., the primitive eusocial bumblebees. Learning in bumblebees has usually been studied under free-flying conditions (Gumbert 2000; Fauria et al. 2002; Spaethe and Chittka 2003; Raine and Chittka 2008) that allow observations in more natural situations, but has the disadvantage of limited control over interindividual interactions and environmental effects. A method that provides the opportunity of Pavlovian (classical) conditioning under strictly controlled environmental conditions represents the proboscis extension response (PER) assay (Kuwabara 1957; for review see Giurfa and Sandoz 2012). The PER assay is well established in honeybee olfactory learning (Bitterman et al. 1983) and has recently been adapted for bumblebees (Laloi et al. 1999; Riveros and Gronenberg 2009b; Toda et al. 2009). Interestingly, recent findings by Laloi and Pham-Delègue (2004) provide evidence that bumblebees exhibit a strong learning asymmetry when they are asked to discriminate two different floral odors in a differential conditioning assay (Laloi and Pham-Delègue 2004). This effect has been reported in honeybees only when bees have to distinguish between one floral and one pheromonal odor (Sandoz et al. 2001) or between odors of different concentrations (Bhagavan and Smith 1997). Furthermore, honeybees and bumblebees also differ in solving complex learning tasks, with honeybees reaching a higher overall olfactory learning performance (Bitterman et al. 1983; Jakobsen et al. 1995; Laloi et al. 1999) and acting fast, but more inaccurate in decision making (Morawetz and Spaethe 2012). While honeybees perform remarkably well in solving complex non-elemental learning tasks (Deisig et al. 2001; Giurfa 2007), only little is known about these skills in bumblebees.

In this study, we first aimed to investigate whether asymmetrical discrimination is a general trait in bumblebees when facing different floral odors (perhaps due to different innate biological meanings of the respective odors; Laloi and Pham-Delègue 2004), as it was found in solitary stingless bees (Mc Cabe and Farina 2010). Second, we intended to evaluate the abilities of bumblebees to solve complex nonelemental olfactory learning tasks, e.g., when they have to discriminate stimuli comprising of more than one odor component.

\section{MATERIALS AND METHODS}

\subsection{Animals and setup}

Colonies of Bombus terrestris (Koppert B. V., Netherlands) were kept in a two-chambered nest box (each chamber was $240 \times 210 \times 110 \mathrm{~mm}$ in size) at $25{ }^{\circ} \mathrm{C}$ and $70 \%$ relative humidity under a $12 / 12 \mathrm{~h}$ photoperiod. Commercially available Apiinvert (a mixture of sucrose, fructose, and glucose) and pollen was provided ad libitum. Individual workers of unknown age and various sizes (inter-tegula span between 2.7 and $4.6 \mathrm{~mm}$ ) were captured and chilled on ice for $45 \mathrm{~min}$. They were then harnessed in tubes (7 $\mathrm{mm}$ in diameter, $35 \mathrm{~mm}$ in length) and fixed with a "yoke" made from a paper clip (adapted from Riveros and Gronenberg 2009b), leaving the head free to enable stimulus perception and proboscis extension. After fixation, individuals were allowed to feed ad libitum on a $0.5 \mathrm{M}$ sucrose solution and were kept for $18 \mathrm{~h}$ at $20{ }^{\circ} \mathrm{C}$ and $70 \%$ relative humidity. Before the experiment started, individuals were tested for a proper PER by carefully touching the antennae with a toothpick soaked with $0.5 \mathrm{M}$ sucrose solution. Only individuals showing a PER were used for further experiments and treated following a standard protocol for olfactory conditioning in bees (Bitterman et al. 1983; Laloi et al. 1999; Deisig et al. 2001; Riveros and Gronenberg 2009b). Bumblebees were placed one 
at a time in front of an exhaust system that ensured the extraction of any residual odor and rested for $20 \mathrm{~s}$ to become familiarized. The respective odorants were diluted 1:100 in paraffin oil. This concentration was chosen to avoid habituation or repelling effects and has been used in other studies (Wright et al. 2009; Reinhard et al. 2010; Brill et al. 2013). Five microliter of the diluted odor was applied to a $2 \times 20 \mathrm{~mm}$ piece of filter paper and placed in a $20 \mathrm{ml}$ plastic syringe. Odor was applied for $6 \mathrm{~s}$, and, after touching the antennae with the wetted toothpick, $0.5 \mathrm{M}$ sucrose solution was presented simultaneously for $3 \mathrm{~s}$ after a delay of $3 \mathrm{~s}$, and the bee was allowed to lick. Afterwards, the bee could rest for another $15 \mathrm{~s}$ and was then replaced by the next individual. The used intertrial interval (ITI) was $8 \mathrm{~min}$ (see also Bitterman et al. 1983; Deisig et al. 2001; using 8 min ITI; Riveros and Gronenberg 2009b; using $10 \mathrm{~min}$ ITI). An extension of the proboscis during the odor presentation and before sucrose delivery was scored as a positive response.

For the CS, we used four different common floral odors (Knudsen et al. 1993) which were also used in earlier studies (1-nonanol (>99.5\%), linalool (>95\%; both Fluka, St. Louis, USA), citral (96\%), and phenylacetaldehyde ( $>90 \%$; both Sigma-Aldrich, Taufkirchen, Germany)) (Deisig et al. 2001; Laloi and Pham-Delègue 2004; Hussaini et al. 2007; Dacher and Smith 2008).

\subsection{Absolute conditioning}

To prove that the four tested odors can be learned to a comparable extent, bumblebees were first trained in an absolute conditioning paradigm. For each odor (citral, 1-nonanol, linalool, and phenylacetaldehyde), two groups of randomly chosen bumblebees were tested. One group was subjected to a forward paired presentation of CS and US, and a control group to an unpaired presentation of the same stimuli. The paired group was trained with ten conditioning trials as described above. Bees of the unpaired group underwent the identical protocol, but with a total of 20 trials, consisting of 10 CS-only trials and 10 USonly trials, presented in a pseudo-randomized order. During CS-only trials, solely the odor was applied for $6 \mathrm{~s}$, whereas during US-only trials, only the sucrose solution was presented for $3 \mathrm{~s}$. With this procedure, an equal number of stimuli presentations in paired and unpaired groups were assured. To exclude that the bumblebees learned the air flow as the CS, an additional control group was trained to pure paraffin, but did not learn at all (see electronic supplemental material, Fig. S1). The final number of individuals used for the experiments was $N=25-37$ in the paired group and $N=12-14$ in the unpaired group.

\subsection{Differential conditioning}

The bumblebees' ability to discriminate between different floral odors was tested in a differential conditioning paradigm. Using the same protocol as described above, each individual was given ten reinforced conditioning trials with one odor as the rewarded stimulus ( $\mathrm{S}+$ ) and ten unreinforced trials with a second odor ( $\mathrm{S}-$ ), presented in a pseudo-randomized order. In addition, a second group of bees was trained in a balanced manner, i.e., the meaning (which odor was $\mathrm{S}+$ and which $\mathrm{S}-$, respectively) of the same odor stimuli was reciprocally changed. Experiments were done with the odor pairs citral vs. 1-nonanol and linalool vs. phenylacetaldehyde, respectively. The total number of individuals subjected to the experimental procedure was $N=25-26$ per group.

\subsection{Positive and negative patterning discrimination}

To study whether bumblebees possess the ability to solve complex learning tasks, two groups of bumblebees were tested in either a positive $\left(\mathrm{A}^{-}, \mathrm{B}^{-}, \mathrm{AB}^{+}\right)$or negative $\left(\mathrm{A}+, \mathrm{B}+, \mathrm{AB}^{-}\right)$pattern discrimination paradigm. In this experiment, the odors citral and 1-nonanol were tested. In the first group (positive patterning group), the presentation of the pure odorants $\left(\mathrm{A}^{-}, \mathrm{B}^{-}\right)$ remained unrewarded, whereas the presentation of the odor mixture $(\mathrm{AB}+)$ was reinforced by a sucrose reward. The second group (negative patterning group) was subjected to the same odor presentations, but here, the individual odors were rewarded $(\mathrm{A}+, \mathrm{B}+)$, and the mixture remained unrewarded $\left(\mathrm{AB}^{-}\right)$. Each bee underwent 32 trials, consisting of 8 presentations of citral alone, 8 presentations of 1-nonanol alone, and 16 presentations of the mixture. With this procedure, the bees were faced an equal number of $\mathrm{CS}+$ and $\mathrm{CS}_{-}^{-}$ presentations (for honeybees, see Deisig et al. 2001). The sequence of $\mathrm{CS}+$ and $\mathrm{CS}-$ trials was pseudo- 
randomized with no more than two repeats of the same stimulus presentation in a row.

\subsection{Learning abilities and body size}

To test if body size correlates with learning performance, the size of each individual was estimated by measuring intertegulae span (Kapustjanskij et al. 2007). Intertegulae span was correlated with three measures of learning performance: the total number of correct responses for each individual and the occurrence of the first response to the $\mathrm{CS}+$ (in absolute and differential conditioning; Riveros and Gronenberg (2009a)), as well as the discrimination index (DI; in differential conditioning and the patterning discrimination tasks). The DI was calculated as the sum of an individual's responses to the CS+ minus the sum of its responses to the CS- (see Pelz et al. 1996).

\subsection{Data analysis}

Statistical analysis was performed on the sum of an individual's responses during all conditioning trials. Each individual was ranked according to its number of correct responses (0-9 in experiments 1 and $2 ; 0-15$ in experiment 3 ). In the first experiment, the ranks of the individuals were compared between the paired and the unpaired group using a Mann-Whitney $U$ test and among different odors using a Kruskal-Wallis test. For the second experiment, the ranks were compared between the responses to the rewarded and the unrewarded stimulus, using a Wilcoxon test. A Wilcoxon test was also applied in the third experiment, where the ranks of the responses to the rewarded and the unrewarded stimulus were compared. Additionally, a $\chi^{2}$-test was used to compare the number of responders to the CS+ and the $\mathrm{CS}-$ in the final conditioning trial (trial number 16) in the third experiment. Correlation of learning performance (measured as total number of correct responses, the occurrence of the first correct response, and as the DI) and body size was tested by a Spearman correlation test.

\section{RESULTS}

Almost all bees survived the $18 \mathrm{~h}$ resting period, and about $30 \%$ of them showed a proper PER when sucrose solution was delivered to the antennae and could be used in the following experiments.

\subsection{Absolute conditioning}

Bumblebee workers responded significantly more often to the CS odor in the paired than in the unpaired group (citral: $Z=-3.856, P<0.001$; 1-nonanol: $Z=-3.947, \quad P<0.001$; phenylacetaldehyde: $Z=-3.418, P<0.001$; and linalool: $Z=-3.627, P<0.001)$ and reached a mean response level of ca. $60 \%$ after ten trials (Figure 1). Cross comparison among odors revealed no significant differences in learning performance $\left(\chi^{2}=0.13, P>0.05, N=114\right)$.

\subsection{Differential conditioning}

Individuals trained with one rewarded $(\mathrm{S}+)$ and one unrewarded odor (S-) could significantly discriminate between both stimuli (Figures 2 and 3). Bees responded to the $\mathrm{S}+$ at a similar level observed in absolute conditioning, whereas almost no response to the $\mathrm{S}$ - occurred (Figures 2 and 3). Interestingly, bees in all experimental groups learned equally well independent of what odor was presented as the rewarded or unrewarded one $(\operatorname{citral}(+)$ vs. 1nonanol(-): $Z=-3.736, P<0.001, \mathrm{DI}=5.4 ; 1-$ nonanol(+) vs. citral (-): $Z=-3.850, P<0.001$, $\mathrm{DI}=5.6$; linalool $(+)$ vs. phenylacetaldehyde $(-)$ : $Z=-3.631, \quad P<0.001, \quad \mathrm{DI}=5.4$; and phenylacetaldehyde(+) vs. linalool(-): $Z=-3.310$, $P=0.001$, DI $=5.4)$. Learning performance did not differ among the four experimental groups $\left(\chi^{2}=1.71, P>0.05, N=101\right)$. We found no evidence for asymmetrical learning in any of the odor combinations.

\subsection{Positive and negative patterning discrimination}

When bumblebees had to solve the positive pattern discrimination task, they were able to distinguish between the reinforced mixture and the non-reinforced single odorants $(Z=-4.563$, $P<0.001$; on trial 16: $\chi^{2}=4.08, P=0.043$; Figure 4$)$. In contrast, in the negative patterning 

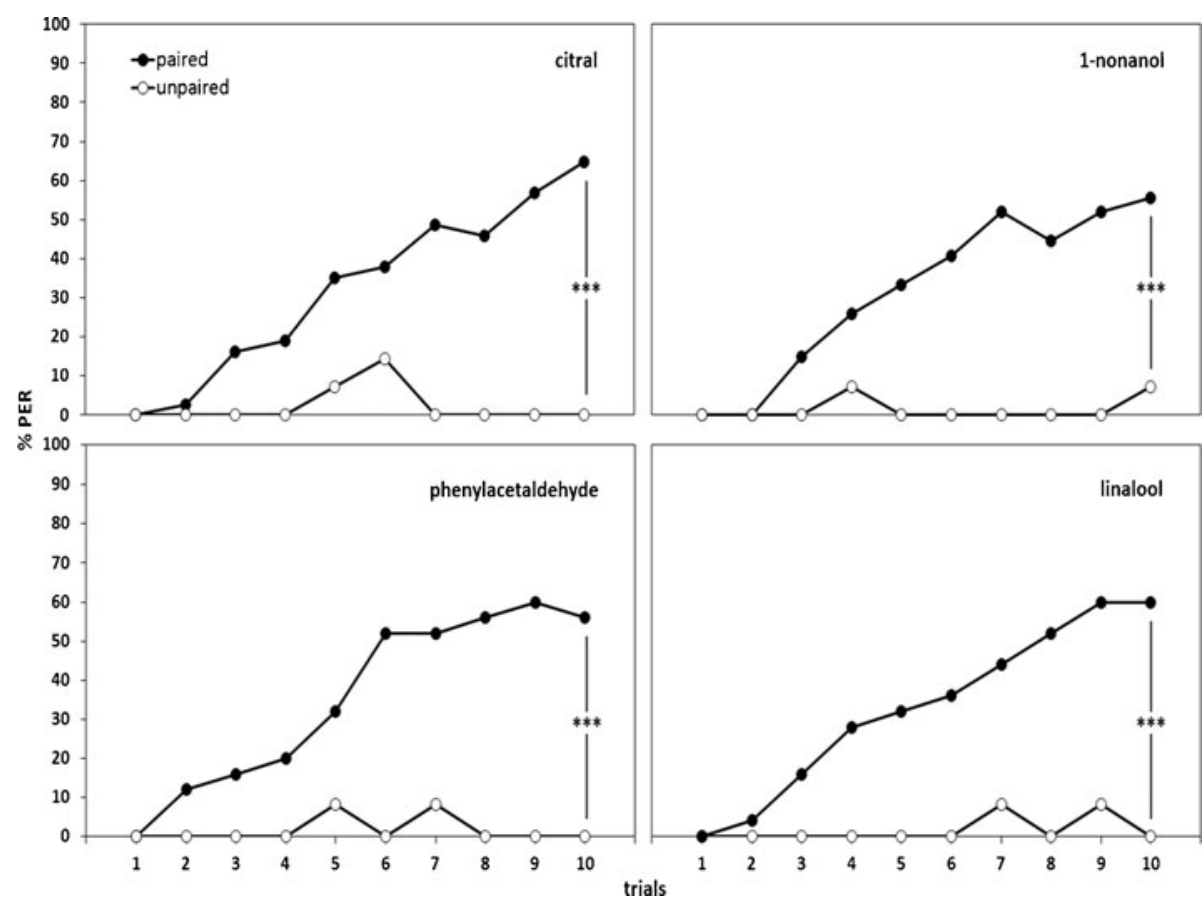

Figure 1. Proboscis extension response ( $P E R)$ during absolute conditioning of four different odors. Bumblebees were trained either paired or unpaired (see Material and methods) with the odors citral (paired: $N=37$; unpaired: $N=14$ ), 1-nonanol $(N=27, N=14)$, phenylacetaldehyde $(N=25, N=12)$, and linalool $(N=25, N=12)$, respectively. Learning performance did not differ among odors (see text for statistics). ${ }^{* * *} P<0.001$.

discrimination task, bumblebees failed to discrimthe unrewarded mixture $(Z=-1.758, P>0.05$ and inate between the rewarded single odorants and on trial 16: $\chi^{2}=0.13, P>0.05$; Figure 4$)$. None of
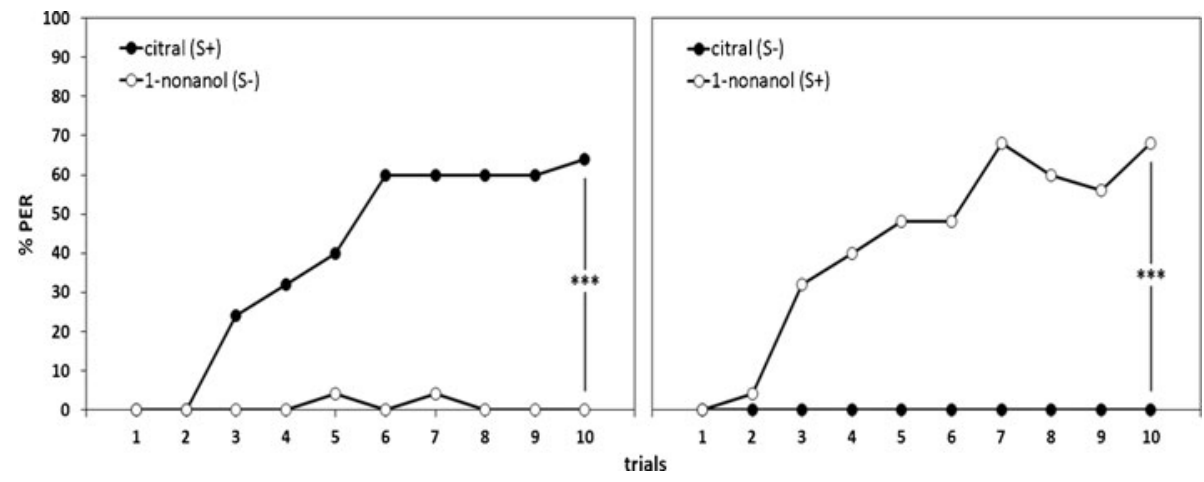

Figure 2. Proboscis extension response across trials of differential conditioning with the odors citral vs. 1-nonanol. On the left, workers $(N=25)$ were trained with citral as the rewarded stimulus $(\mathrm{S}+)$ and 1-nonanol as the unrewarded stimulus $(\mathrm{S}-)$; in the right panel, both odors were interchanged $(N=25)$. The learning performance did not differ between both situations (see text for statistics). ${ }^{* * *} P<0.001$. 


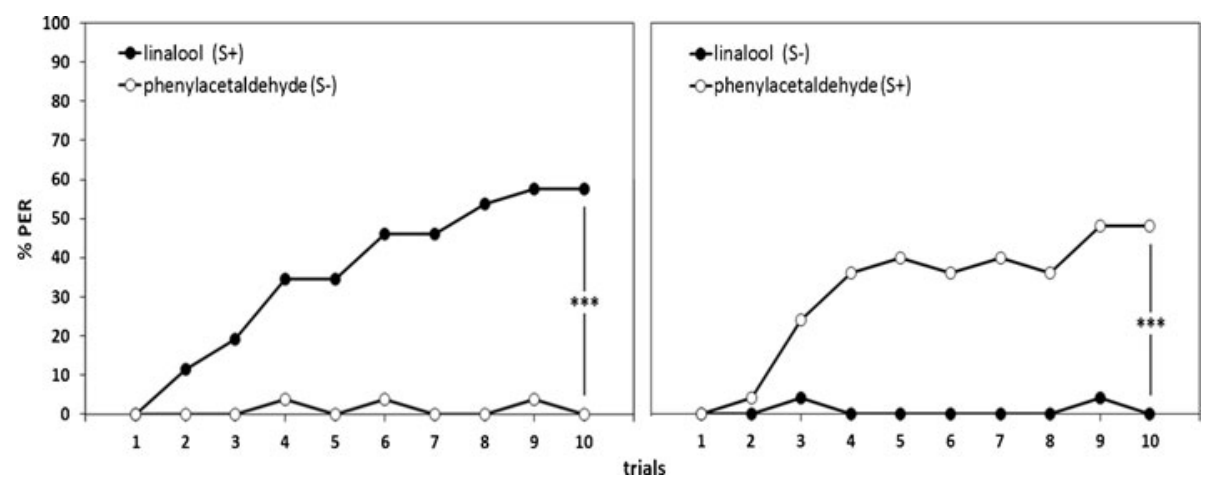

Figure 3. Proboscis extension response across trials of differential conditioning with the odors linalool vs. phenylacetaldehyde. On the left, linalool was the rewarded stimulus $(\mathrm{S}+)$ and phenylacetaldehyde the unrewarded stimulus $\left(\mathrm{S}^{-}\right)(N=26)$; in the right panel, both odors were interchanged $(N=25)$. No significant differences were found between the two groups (see text for statistics). $* * * P<0.001$.

the bees tested performed the task correctly (for all individuals DI was $\leq 2$ ).

\subsection{Learning abilities and body size}

A size-effect on the learning performance was observed for two of the tested odors in the absolute conditioning experiment. When trained to 1-nonanol and phenylacetaldehyde, body size correlated positively with the number of responses ( 1 - nonanol: $\quad \mathrm{r}_{\mathrm{s}}=0.552, \quad P=0.009$; phenylacetaldehyde: $\left.\mathrm{r}_{\mathrm{s}}=0.709, P<0.001\right)$ and negatively with the first response (1-nonanol: $r_{s}=$ $-0.433, P=0.05$; phenylacetaldehyde: $\mathrm{r}_{\mathrm{s}}=-0.765$, $P<0.001)$. In contrast, no size effects were found for citral (size vs. number of responses: $\mathrm{r}_{\mathrm{s}}=-0.230$, $P=0.240$; size vs. first response: $r_{\mathrm{s}}=0.321$, $P=0.096$ ), linalool (size vs. number of responses: $\mathrm{r}_{\mathrm{s}}=-0.091, P=0.710$; size vs. first response: $\mathrm{r}_{\mathrm{s}}=$ $-0.245, P=0.312$ ), and in all of the other experiments (differential conditioning and pattern discrimination; all $P>0.05$ ).

\section{DISCUSSION}

We could show that workers of $B$. terrestris are able to solve the absolute conditioning task, i.e., they are able to associate a specific odor with a sugar reward. The learning performance reached a level of more than $50 \%$ correct responses after seven trials and ca. $60 \%$ after ten trials. Previous studies have found a variable learning performance in bumblebees, ranging from ca. 20-30\% in B. terrestris (Laloi et al. 1999) to $50-70 \%$ in Bombus occidentalis (Riveros and Gronenberg $2009 b$ ). These differences might be due to methodological (e.g., starvation period, amount and concentration of sugar solution, and mounting procedure; Toda et al. 2009) or species-specific differences (see below).

In our study, we found no differences in the memory acquisition curves and the learning performance among different odor groups (Figure 1). Thus, stimulus reception, processing, and memory acquisition in the absolute conditioning essay seem to be similar for all tested odors. Our findings also suggest that, in contrast to previous studies, $B$. terrestris shows only a slightly poorer learning performance compared to honeybees both in speed (slope of learning curve) and accuracy (plateau of learning curve) (honeybee: Bitterman et al. 1983; B. terrestris: Laloi et al. 1999; B. occidentalis: Riveros and Gronenberg 2009b).

Interestingly, bumblebees were able to learn both odor combinations in the differential conditioning essay equally well, irrespective of which odor was the rewarding or unrewarding stimulus (Figures 2 and 3). After seven trials, the average response level reached 50-60\% and thus was 


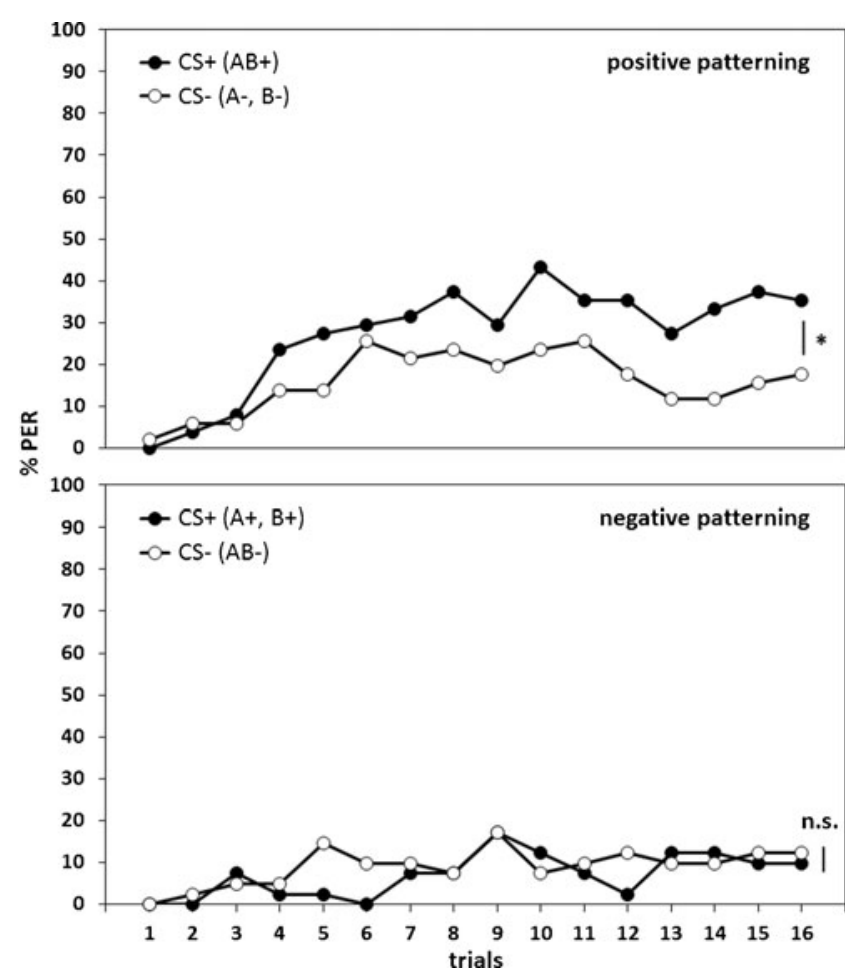

Figure 4. Proboscis extension response during trials of positive $(N=51)$ and negative $(N=41)$ patterning discrimination. In the upper panel, the individual odors (citral, 1-nonanol; CS-) remained unrewarded, while the compound $(\mathrm{CS}+)$ of both odors was reinforced. Individuals learned to discriminate between $\mathrm{CS}+$ and $\mathrm{CS}-$. In contrast, in the lower panel the individual odors were rewarded (CS+), while the compound (CS-) remained unrewarded. Here, the bees were not able to discriminate between CS+ and CS- (see text for statistics). * $P<0.05 ; n s$, not significant.

similar to the level found in the absolute conditioning essay. Our results contrast with Laloi and Pham-Delègue (2004), who reported an asymmetrical discrimination effect in bumblebees when using linalool and phenylacetaldehyde. They found that bumblebees could easily discriminate between both stimuli when linalool was the rewarded stimulus and phenylacetaldehyde was the unrewarded one, but failed when the odors were exchanged. This discrepancy might be explained by various factors, for example, experimental procedure, colony specificity, or starvation level of the tested bumblebees. In the study by Laloi and Pham-Delègue (2004), bees were starved for a shorter time than in our case and most other studies (5 h vs. $12-18 \mathrm{~h}$; Riveros and Gronenberg 2009b; Anfora et al. 2011) and were probably fixed in a way usually used for honeybees (although a detailed description is missing in their paper). Both factors strongly affect PER performance (Bitterman et al. 1983; Toda et al. 2009; Matsumoto et al. 2012) and may, thus, explain the overall low response level of ca. $30 \%$.

Furthermore, our findings provide evidence that bumblebees manage to discriminate between single odors and mixtures containing the same odors in an appetitive positive patterning discrimination task. In contrast, our bees were not able to differentiate between single odorants and mixtures containing the same odors in the negative patterning approach. These results indicate deficiencies in configural learning abilities, compared to honeybees. While Deisig et al. (2001) demonstrated that honeybees solved both positive and 
negative discrimination tasks, whereas bumblebees failed to solve the more complex latter task in our experiment. A positive patterning discrimination $(\mathrm{A}-, \mathrm{B}-\mathrm{vs} . \mathrm{AB}+)$ can still be accomplished by elemental learning, since the response threshold could be exceeded by the associative strength of the combined elements, but not by that of each single element (elemental summation principle; Deisig et al. 2001). In contrast, solving the negative pattern discrimination $\left(\mathrm{A}+, \mathrm{B}+\mathrm{vs} . \mathrm{AB}^{-}\right)$ can only be achieved by a configural approach, since the sum of the associative strengths of the elements of a complex CS would always be greater than that of the single elements themselves, i.e., individuals would respond more often to the "stronger" mixture than to the "weaker" single elements (for review see Pearce and Bouton 2001). However, in our experiments, bumblebees failed to process configural associations, and it seems that they cope with complex olfactory learning tasks in an elemental manner. Interestingly, bumblebees indeed possess configural learning abilities when they must associate a reward with visual stimuli in a complex task (Fauria et al. 2002). Although the neural mechanisms of the different learning strategies are still unclear, differences between honeybees and bumblebees can be considered in an ecological context, as they differ in the evaluation of stimuli modalities. While honeybees possess a pronounced flower constancy during a single foraging trip and rely stronger on olfactory cues (Grant 1950; Jakobsen et al. 1995), bumblebees are less faithful to one floral type and focus more on spatial information (Free 1970; Jakobsen et al. 1995; Raine and Chittka 2007). Thus, bumblebees may rely more on common floral cues like colors or shapes rather than species-specific odors when foraging and hence perform better in complex configural learning tasks when facing conditioned stimuli of non-olfactory modalities, e.g., visual or tactile stimuli.

A remarkable characteristic of bumblebees is the distinct size polymorphism of workers within a colony. Workers in our study differed in their intertegulae span by a factor of 1.7 (ranging from 2.7 to $4.6 \mathrm{~mm}$ ). Our data revealed a significant correlation between body size and learning performance only in two experimental groups when the reinforced odor in absolute conditioning was 1-nonanol and phenylacetaldehyde, respectively. In general, this effect might be explained by differences in perceptual sensitivity between larger and smaller individuals (Spaethe et al. 2007). However, no size effect was observed either in the other absolute conditioning experiments or in the differential conditioning assays. This is consistent with the study by Raine and Chittka (2008), who found no correlations between body size and learning speed in $B$. terrestris under free-flying conditions. In contrast, some previous studies reported positive correlations between size and learning performance in B. impatiens (Worden et al. 2005) and size and memory consolidation in $B$. occidentalis (Riveros and Gronenberg 2009b). Taken together, these results suggest a distinct interspecific variation, although a more systematic evaluation of the size effect on various measures of learning performance (learning speed, maximum performance level, etc.) in different Bombus species is needed in future studies.

To summarize, we could show that PER conditioning is a well-suited paradigm for the investigation of memory acquisition and olfactory learning in $B$. terrestris under fully controlled environmental conditions. Bumblebees perform in absolute and differential olfactory conditioning in a way comparable to honeybees, but fail when facing a complex negative pattern discrimination task. Future studies should fathom the proximate and ultimate causes underlying the species-specific learning capabilities, in particular with respect to differences in the species' ecology and life history.

\section{ACKNOWLEDGMENTS}

We would like to thank Karin Möller for rearing the bumblebees. We also thank two anonymous reviewers for their helpful comments on an earlier draft of this manuscript. This work was supported by a $\mathrm{PhD}$ research scholarship offered by the Free State of Bavaria (Elitenetzwerk Bayern) to FMJS. 
Apprentissage olfactif de base ou complexe par conditionnement du REP (réflexe d'extension du proboscis) chez le bourdon, Bombus terrestris

\author{
Apprentissage élémentaire / bourdon / REP / associations \\ configurales
}

Elementares und nicht-elementares olfaktorisches Lernen bei der PER-Konditionierung der Hummel Bombus terrestris

Elementares Lernen / Bombus terrestris / Rüsselreflexkonditionierung / Hummel / konfigurale Assoziationen

\section{REFERENCES}

Anfora, G., Rigosi, E., Frasnelli, E., Ruga, V., Trona, F., Vallortigara, G. (2011) Lateralization in the invertebrate brain: left-right asymmetry of olfaction in bumble bee, Bombus terrestris. PLoS One 6(4), e18903

Bhagavan, S., Smith, B.H. (1997) Olfactory conditioning in the honeybee, Apis mellifera: effects of odor intensity. Physiol. Behav. 61(1), 107-117

Bitterman, M.E., Menzel, R., Fietz, A., Schäfer, S. (1983) Classical conditioning of proboscis extension in honeybees (Apis mellifera). J. Comp. Psychol. 97(2), 107-119

Brill, M.F., Rosenbaum, T., Reus, I., Kleineidam, C.J., Nawrot, M.P., Rössler, W. (2013) Parallel processing via a dual olfactory pathway in the honeybee. J. Neurosci. 33(6), 2443-2456

Couvillon, P.A., Bitterman, M.E. (1988) Compoundcomponent and conditional discrimination of colors and odors by honeybees: Further tests of a continuity model. Anim. Learn. Behav. 16(1), 67-74

Dacher, M., Smith, B.H. (2008) Olfactory interference during inhibitory backward pairing in honeybees. PLoS One 3(10), e3513

Deisig, N., Lachnit, H., Giurfa, M. (2001) Configural olfactory learning in honeybees: negative and positive patterning discrimination. Learn. Mem. 8, 70-78

Deisig, N., Lachnit, H., Giurfa, M. (2002) The effect of similarity between elemental stimuli and compounds in olfactory patterning discriminations. Learn. Mem. 9(3), 112-121

Deisig, N., Lachnit, H., Sandoz, J.C., Lober, K., Giurfa, M. (2003) A modified version of the unique cue theory accounts for olfactory compound processing in honeybees. Learn. Mem. 10(3), 199-208
Dukas, R. (2008) Evolutionary biology of insect learning. Annu. Rev. Entomol. 53, 145-160

Fauria, K., Dale, K., Colborn, M., Collett, T. (2002) Learning speed and contextual isolation in bumblebees. J. Exp. Biol. 205, 1009-1018

Free, J.B. (1970) The flower constancy of bumblebees. J. Anim. Ecol. 39(2), 395-402

Giurfa, M. (2003) Cognitive neuroethology: dissecting non-elemental learning in a honeybee brain. Curr. Opin. Neurobiol. 13(6), 726-735

Giurfa, M. (2007) Behavioral and neural analysis of associative learning in the honeybee: a taste from the magic well. J. Comp. Physiol. A .Neuroethol. Sens. Neural. Behav. Physiol. 193(8), 801-824

Giurfa, M., Sandoz, J.C. (2012) Invertebrate learning and memory: fifty years of olfactory conditioning of the proboscis extension response in honeybees. Learn. Mem. 19(2), 54-66

Grant, V. (1950) The flower constancy of bees. Bot. Rev. 16(7), 379-398

Gumbert, A. (2000) Color choices by bumble bees (Bombus terrestris): innate preferences and generalization after learning. Behav. Ecol. Sociobiol. 48, 36-43

Hussaini, S.A., Komischke, B., Menzel, R., Lachnit, H. (2007) Forward and backward second-order Pavlovian conditioning in honeybees. Learn. Mem. 14(10), 678-683

Jakobsen, H.B., Kristiánsson, K., Rohde, B., Terkildsen, M., Olsen, C.E. (1995) Can social bees be influenced to choose a specific feeding station by adding the scent of the station to the hive air? J. Chem. Ecol. 21(11), 1635-1648

Kapustjanskij, A., Streinzer, M., Paulus, H.F., Spaethe, J. (2007) Bigger is better: implications of body size for flight ability under different light conditions and the evolution of alloethism in bumblebees. Funct. Ecol. 21(6), 1130-1136

Knudsen, J.T., Tollsten, L., Bergström, L.G. (1993) Floral Scents - a checklist of volatile compounds isolated by head-space techniques. Phytochemistry 33(2), 253-280

Komischke, B., Sandoz, J.-C., Lachnit, H., Giurfa, M. (2003) Non-elemental processing in olfactory discrimination tasks needs bilateral input in honeybees. Behav. Brain Res. 145(1-2), 135-143

Kuwabara, M. (1957) Bildung des bedingten Reflexes von Pavlovs Typus bei der Honigbiene Apis mellifera. J. Fac. Scie. Hokkaido Univ. Ser. VI Zool. 13, 458-464

Laloi, D., Bailez, O., Blight, M.M., Roger, B., PhamDelègue, M.H., Wadhams, L.J. (2000) Recognition of complex odors by restrained and free-flying honeybees, Apis mellifera. J. Chem. Ecol. 26(10), 2307-2319

Laloi, D., Pham-Delègue, M.H. (2004) Bumblebees show asymmetrical discrimination between two odors in a classical conditioning procedure. J. Insect Behav. 17(3), 385-396

Laloi, D., Sandoz, J.C., Picard-Nizou, A.L., Marchesi, A., Pouvreau, A., Taséi, J.N., Poppy, G., Pham-Delègue, 
M.H. (1999) Olfactory conditioning of the proboscis extension in bumble bees. Entomol. Exper. Appl. 90, $123-129$

Matsumoto, Y., Menzel, R., Sandoz, J.C., Giurfa, M. (2012) Revisiting olfactory classical conditioning of the proboscis extension response in honey bees: a step toward standardized procedures. J. Neurosci. Methods 211(1), 159-167

Mc Cabe, S.I., Farina, W.M. (2010) Olfactory learning in the stingless bee Tetragonisca angustula (Hymenoptera, Apidae, Meliponini). J. Comp. Physiol. A Neuroethol. Sens. Neural. Behav. Physiol. 196(7), 481-490

Menzel, R., Giurfa, M., Gerber, B., Hellstern, F. (1999) Elementary and configural forms of memory in an insect: the honeybee. In: Friederici, A.D., Menzel, R. (eds.) Learning: Rule Extraction and Representation, pp. 259-282. Walter de Gruyter, Berlin, New York

Menzel, R., Müller, U. (1996) Learning and memory in honeybees: from behavior to neural substrates. Annu. Rev. Neurosci. 19, 379-404

Morawetz, L., Spaethe, J. (2012) Visual attention in a complex search task differs between honeybees and bumblebees. J. Exp. Biol. 215(Pt 14), 2515-2523

Pearce, J.M. (1987) A Model for stimulus generalization in Pavlovian conditioning. Psychol. Rev. 94(1), 61-73

Pearce, J.M., Bouton, M.E. (2001) Theories of associative learning in animals. Annu. Rev. Psychol. 52, 111-139

Pelz, C., Gerber, B., Menzel, R. (1996) Odorant intensity as a determinant for olfactory conditioning in honeybees: roles in discrimination, over-shadowing, and memory consolidation. J. Exp. Biol. 200, 837-847

Raine, N.E., Chittka, L. (2007). Flower Constancy and memory dynamics in bumblebees (Hymenoptera: Apidae: Bombus). Entomol. Gen. 29(2-4), 179-199

Raine, N.E., Chittka, L. (2008) The correlation of learning speed and natural foraging success in bumblebees. Proc. Biol. Sci. 275(1636), 803-808

Reinhard, J., Sinclair, M., Srinivasan, M.V., Claudianos, C. (2010) Honeybees learn odor mixtures via a selection of key odorants. PLoS One 5(2), e9110
Rescorla, R.A. (1972) "Configural" conditioning in discrete-trial bar pressing. J. Comp. Physiol. Psychol. 79(2), 307-317

Rescorla, R.A., Wagner, A.R. (1972) A theory of Pavlovian conditioning: variations in the effectiveness of reinforcement and non-reinforcement. In: Black, A.H., Prokasy, W.F. (eds.) Classical Conditioning 2: Current research and theory, pp. 64-99. Appleton, New York

Riveros, A.J., Gronenberg, W. (2009a) Learning from learning and memory in bumblebees. Commun. Integr. Biol. 2(5), 437-440

Riveros, A.J., Gronenberg, W. (2009b) Olfactory learning and memory in the bumblebee Bombus occidentalis. Naturwissenschaften 96(7), 851-856

Rudy, J.W., Sutherland, R.J. (1992) Configural and elemental associations and the memory coherence problem. J. Cogn. Neurosci. 4(3), 208-216

Sandoz, J.C., Pham-Delègue, M.H., Renou, M., Wadhams, L.J. (2001) Asymmetrical generalization between pheromonal and floral odors in appetitive olfactory conditioning of the honeybee (Apis mellifera L.). J. Comp. Physiol. A 187, 559-568

Spaethe, J., Brockmann, A., Halbig, C., Tautz, J. (2007) Size determines antennal sensitivity and behavioral threshold to odors in bumblebee workers. Naturwissenschaften 94(9), 733-739

Spaethe, J., Chittka, L. (2003) Interindividual variation of eye optics and single object resolution in bumblebees. J. Exper. Biol. 206(19), 3447-3453

Toda, N.R., Song, J., Nieh, J.C. (2009) Bumblebees exhibit the memory spacing effect. Naturwissenschaften 96(10), 1185-1191

Wagner, A.R., Rescorla, R.A. (1972) Inhibition in Pavlovian conditioning: application of a theory. In: Halliday, M.S., Boakes, R.A. (eds.) Inhibition and learning, pp. 301-336. Academic, London

Worden, B.D., Skemp, A.K., Papaj, D.R. (2005) Learning in two contexts: the effects of interference and body size in bumblebees. J. Exp. Biol. 208(Pt 11), 2045-2053

Wright, G.A., Carlton, M., Smith, B.H. (2009) A honeybee's ability to learn, recognize, and discriminate odors depends upon odor sampling time and concentration. Behav. Neurosci. 123(1), 36-43 